\title{
A SPATIAL-TEMPORAL ESTIMATION MODEL OF RESIDUAL ENERGY FOR PURE ELECTRIC BUSES BASED ON TRAFFIC PERFORMANCE INDEX
}

\author{
Li Wang, Jingfeng Yang, Nanfeng Zhang, Ji Yang, Yong Li, Jiarong He, Feng Yang, Handong Zhou
}

\begin{abstract}
Original scientific paper
The relationship between the energy consumption of buses and traffic conditions has gradually garnered research attention with the expansion of the green transportation concept and the promotion of new energy buses. In line with these developments, this study develops a spatial-temporal estimation model of residual energy for pure electric buses with fuzzy clustering and time-series algorithms. These algorithms are based on the traffic performance index of the road sections between the nearest bus stops. Furthermore, they are established according to the positions of floating vehicles and the bus routes in combination with the energy consumption data derived from the battery management system of pure electric buses. Test results show that these estimation algorithms can accurately describe the spatial-temporal relationship between traffic performance index and the residual energy in pure electric buses. Thus, they can be applied as significant references in the analysis of traffic conditions, energy conservation, and emission reduction for buses.
\end{abstract}

Keywords: fuzzy clustering; fuzzy time series; pure electric bus; residual energy; traffic index

Prostorno-vremenski model procjene preostale energije za potpuno električne autobuse na temelju indeksa učinka prometa

Izvorni znanstveni članak Odnos između potrošnje energije autobusa i prometnih uvjeta postupno je privukao istraživačku pozornost sa širenjem koncepta zelenog transporta promocijom novih energetskih autobusa. U skladu s ovim razvojem, ova studija razvija prostorno-vremenski model procjene preostale energije za potpuno električne autobuse s algoritmima neizrazitog grupiranja i neizrazitim vremenskim nizovima. Ovi algoritmi se temelje na indeksu učinka prometa cestovnih dionica između najbližih autobusnih stanica. Nadalje, oni se uspostavljaju prema položajima vozila u prometu i autobusnim rutama u kombinaciji s podacima o potrošnji energije koji proizlaze iz sustava upravljanja baterijama potpuno električnih autobusa. Rezultati ispitivanja pokazuju da ti algoritmi procjene mogu točno opisati prostorno-vremenski odnos između indeksa učinka prometa i preostale energije u potpuno električnim autobusima. Tako se oni mogu primijeniti kao značajne reference u analizi prometnih uvjeta, očuvanja energije i smanjenja emisija za autobuse.

Ključne riječi: indeks prometa; neizrazito grupiranje; neizraziti vremenski nizovi; potpuno električni autobus; preostala energija

\section{Introduction}

Pure electric buses have developed rapidly under China's current energy conservation and emission reduction policy. However, they remain under trial operation and their large-scale use has not been promoted given the limited driving mileage, which is limited by battery capacity and operational conditions. As such, researchers have analyzed and evaluated driving mileage under the current conditions using various methods; however, they have yet to report a breakthrough with respect to battery storage capacity and reliability. Currently, driving mileage is mainly estimated precisely by converting accurate SOC (State of Charge, it means a battery is its available capacity expressed as a percentage of its rated capacity) values. Therefore, studies focus on the accurate estimation of SOC. Some representative algorithms have also been developed in relation to the energy consumption of batteries. For instance, Luo [1] proposed a SOC calculation method that can correct the initial errors associated with the lithium-ion batteries used in electric buses. Tian [2] established an improved model of Partnership for a New Generation of Vehicles for lithium iron phosphate batteries. The SOC for these batteries is estimated accurately using the extended Kalman filter algorithm. Li [3] presented an initial SOC correction algorithm to eliminate accumulated errors in SOC and to enhance accuracy because the initial value strongly influences the ampere-hour integral method of SOC calculation for lithium-iron phosphate batteries. Bingham [4] study investigates the impact of driver behaviour/driving-style on the energy consumption, stateof-charge (SOC) usage and range, of all-electric vehicles
(EVs). Results from many driving cycles using a sole driver, along with those from a predefined $\sim 40 \mathrm{~km}$ route encompassing both urban and rural roads in Sheffield (UK) with various drivers, are given and analysed. Vaz [5] proposes a novel strategy that presents a number of optimal trip speeds to the driver, along with the total trip time corresponding to a predicted range. Hornstra [6] described that which combines the use of the battery Ragone (average power) and peak power characteristics, in a simple manner, to show which batteries and which drive train characteristics favour any one driving schedule over another, including the Federal Urban Driving Schedule (FUDS) and the SAE J227aD Urban Driving Schedule (SUDS). Oliva [7] introduces a model-based approach for predicting the RDR by combining a particle filter with Markov chains. Niu [8] analyzed the parameters of equivalent circuit models and both the voltage and dynamic power characteristics of batteries through electrochemical impedance spectroscopy. This author also determined the typical parameter identification conditions for batteries by comprehensively analysing the main characteristics of charging and discharging conditions. The model parameters were then examined through particle swarm optimization. This study also applied the revised voltmeter-ammeter method [9], the Kalman [10-13], the neural network algorithms $[14,15]$ and the clustering algorithms [16] extensively.

Various factors can influence the energy consumption of pure electric buses, including time interval (morning and evening peaks), road conditions, driving habits, routes, and passengers. Therefore, the present study utilizes the data obtained from currently operating pure electric buses and combines them with the 
traffic index system of bus stops to establish the residual energy prediction model for these buses. The fuzzy clustering and time-series algorithms are also applied to support the planning and adjustment of bus routes, vehicle dispatching, and planning of charging stations strategically.

\section{Traffic performance index}

Real-time traffic performance index has garnered considerable interest in China [17]. These indices are based on smart traffic-data acquisition, processing, and analysis. Furthermore, they are combined with traditional parameters, such as flow rate, density, occupancy rate, and speed. Beijing City and Guangzhou City have released their local technical standards in relation to traffic performance index [18, 19]. Thus, this study comprehensively compares the characteristics of traffic performance index in various cities. Moreover, the calculation considers the mileage ratios of traffic jams on various roads based on the traffic performance index of Guangzhou [19] and on the classification of roads and traffic performance index.

The roads between the nearest bus stops are considered the calculation objects to determine the traffic performance index for these roads according to bus operation law:

$$
\varphi=\frac{\sum_{j=1}^{N_{2}} L_{j}}{\sum_{k=1}^{m} L_{k}},
$$

where $\varphi$ represents the mileage ratio of a heavy traffic jam (when Traffic Performance Index (TPI) values are $6 \leq$ TPI $<8$ ) on the road between the nearest bus stops; $L_{j}$ represents the length of the road that experiences heavy traffic between the nearest bus stops; $N_{2}$ represents the sections of road under heavy traffic between the nearest bus stops; $L_{k}$ represents the length of each section of the road that experiences heavy traffic between the nearest bus stops; and $m$ represents the number of road sections.

The calculation method of the traffic performance index for a single road between the nearest bus stops is similar to that for the traffic performance index of all bus stops overall.

\section{Spatial-temporal algorithm that predicts the residual energy of pure electric buses}

Energy consumption varies on different roads. Therefore, it should be classified according to bus route. Various models should be generated to predict accumulated driving mileage accurately. In line with this objective, the energy consumption of buses in operation can be distributed in terms of bus routes and stops. The distribution of energy consumption in terms of bus routes considers the working conditions of pure electric buses but not the waiting time for entry to and exit from bus stops during operation. Moreover, a large number of bus stops on a route complicate the calculation model of energy consumption. The model of route energy consumption also displays poor stability and robustness because the working condition of the bus on the route is significantly affected by road networks. Given this information, this study constructs a calculation model of energy consumption for the road between the nearest bus stops. The starting point is the bus stop exit and the end point is the bus stop entry. The stability of the established energy consumption model can thus be improved by fully considering road working conditions. Moreover, the energy consumption model of the bus stop can be expanded and extended when bus routes are adjusted.

Table 1 Classification of the factors that influence energy consumption (batteries)

\begin{tabular}{|c|c|c|c|c|c|c|c|c|}
\hline $\begin{array}{c}\text { Classification } \\
\text { of energy } \\
\text { consumption }\end{array}$ & $\begin{array}{c}\text { Remaining } \\
\text { SOC }\end{array}$ & Total voltage & $\begin{array}{c}\text { Maximum } \\
\text { voltage }\end{array}$ & $\begin{array}{c}\text { Minimum } \\
\text { voltage }\end{array}$ & $\begin{array}{c}\text { Maximum } \\
\text { battery } \\
\text { temperature }\end{array}$ & $\begin{array}{c}\text { Minimum } \\
\text { bus } \\
\text { temperature }\end{array}$ & $\begin{array}{c}\text { Total } \\
\text { current }\end{array}$ & $\begin{array}{c}\text { Difference in } \\
\text { voltage }\end{array}$ \\
\hline $\begin{array}{c}\text { Extremely } \\
\text { high } \\
\text { (abnormal) }\end{array}$ & $\leq 40 \%$ & $\geq 600 \mathrm{~V}$ & $\geq 3.32 \mathrm{~V}$ & $\geq 3.30 \mathrm{~V}$ & $\geq 60{ }^{\circ} \mathrm{C}$ & $\leq 20{ }^{\circ} \mathrm{C}$ & $\geq 85.5 \mathrm{~A}$ & $\geq 0.09 \mathrm{~V}$ \\
\hline High & $40 \%-50 \%$ & $590-600 \mathrm{~V}$ & $3.29-3.32 \mathrm{~V}$ & $3.28-3.30 \mathrm{~V}$ & $50-60{ }^{\circ} \mathrm{C}$ & $20-26{ }^{\circ} \mathrm{C}$ & $84.4-85.5 \mathrm{~A}$ & $0.06-0.09 \mathrm{~V}$ \\
\hline Normal & $50 \%-55 \%$ & $570-590 \mathrm{~V}$ & $3.27-3.29 \mathrm{~V}$ & $3.22-3.28 \mathrm{~V}$ & $40-60{ }^{\circ} \mathrm{C}$ & $26-28{ }^{\circ} \mathrm{C}$ & $83.6-84.4 \mathrm{~A}$ & $0.03-0.06 \mathrm{~V}$ \\
\hline Low & $55 \%-65 \%$ & $560-570 \mathrm{~V}$ & $3.21-3.27 \mathrm{~V}$ & $3.18-3.22 \mathrm{~V}$ & $30-40{ }^{\circ} \mathrm{C}$ & $28-30{ }^{\circ} \mathrm{C}$ & $83.0-83.6 \mathrm{~A}$ & $0.01-0.02 \mathrm{~V}$ \\
\hline $\begin{array}{c}\text { Extremely low } \\
\text { (abnormal) }\end{array}$ & $\geq 65 \%$ & $\leq 560 \mathrm{~V}$ & $\leq 3.21 \mathrm{~V}$ & $\leq 3.18 \mathrm{~V}$ & $\leq 30{ }^{\circ} \mathrm{C}$ & $\geq 30{ }^{\circ} \mathrm{C}$ & $\leq 83.0 \mathrm{~A}$ & $\leq 0.01 \mathrm{~V}$ \\
\hline
\end{tabular}

Note: Total voltage and total current refer to the absolute values of the overall measured data for battery packs during electric discharge. The maximum voltage, minimum voltage, and voltage difference refer to the voltages of single batteries. Moreover, the maximum and minimum voltages correspond independently.

The energy consumption of pure electric buses on roads between the nearest bus stops are influenced by the length, current, voltage, and road conditions (traffic performance index) of the route. A standard for energy consumption classification can be established in relation to the influential factors based on relevant research and actual operation data [19-21] for each road between the nearest bus stops. This standard determines energy consumption conditions through seasonal classifications, bus operation plans, traffic laws, driving conditions, the influence of a constant weekly time interval, and the average value of energy consumption on the road between the nearest bus stops. Measured data in Tab. 1 and Tab. 2 are classified according to operating conditions of the buses and experiences of the staff. These classified data are based on the division and statistic of the ecological distribution. Tabs. 1 and 2 show the classifications of the energy consumption conditions of a pure electric bus travelling on a road between the nearest bus stops in the period of June-August. This bus departs at 08:30 hours on 
Monday mornings. Nonetheless, the parameters in the tables are suitable only for the roads between the test bus stops, and they vary for every road between the nearest stops.

A model of route energy consumption can be established based on the road sections between the nearest bus stops after quantizing the main influential factors in the energy consumption of a pure electric bus. This model is meaningful only when it is associated with a certain time and with roads in consideration of time-series data, such as the spatial-temporal correlation of the influential factors and the traffic flow data of pure electric buses as traffic and passenger flows. The mathematical model must determine the laws and data trends that change with time, including time-series trend analysis and cyclic pattern matching.

Table 2 Classification of the factors that influence energy consumption (traffic performance index)

\begin{tabular}{|c|c|c|c|c|c|c|}
\hline $\begin{array}{c}\text { Classification of } \\
\text { energy } \\
\text { consumption }\end{array}$ & $\begin{array}{c}\text { Average speed on } \\
\text { the main road }\end{array}$ & $\begin{array}{c}\text { Average speed } \\
\text { on the subsidiary } \\
\text { road }\end{array}$ & $\begin{array}{c}\text { Indices of } \\
\text { traffic jams }\end{array}$ & $\begin{array}{c}\text { Mileage ratios } \\
\text { of traffic jams }\end{array}$ & $\begin{array}{c}\text { Periods of } \\
\text { traffic jams }\end{array}$ & $\begin{array}{c}\text { Number of road sections } \\
\text { between the nearest bus } \\
\text { stops under traffic jams }\end{array}$ \\
\hline Extremely high & $\leq 20 \mathrm{~km} / \mathrm{h}$ & $\leq 15 \mathrm{~km} / \mathrm{h}$ & $\geq 8$ & $\geq 30 \%$ & $\geq 50 \mathrm{~min}$ & $\geq 7$ \\
\hline High & $20-30 \mathrm{~km} / \mathrm{h}$ & $15-25 \mathrm{~km} / \mathrm{h}$ & $6-8$ & $20-30 \%$ & $30-50 \mathrm{~min}$ & $20-30 \mathrm{~min}$ \\
\hline Normal & $30-40 \mathrm{~km} / \mathrm{h}$ & $25-35 \mathrm{~km} / \mathrm{h}$ & $4-6$ & $10-20 \%$ & $3-6$ \\
\hline Low & $40-50 \mathrm{~km} / \mathrm{h}$ & $35-50 \mathrm{~km} / \mathrm{h}$ & $2-4$ & $5-10 \%$ & $10-20 \mathrm{~min}$ & $\leq 1-2$ \\
\hline Extremely low & $\geq 50 \mathrm{~km} / \mathrm{h}$ & $\geq 50 \mathrm{~km} / \mathrm{h}$ & $\leq 2$ & $\leq 5 \%$ & $\leq 10 \mathrm{~min}$ & \\
\hline
\end{tabular}

Note: All traffic performance indexes refer to those of road sections along the route. All of the data in the table represent the operation indices on work days. The other indices denote the overall conditions of the road in operation, with the exception of the road sections under traffic jam between the nearest bus stops. A traffic jam is characterized by an average road speed of less than $30 \mathrm{~km} / \mathrm{h}$.

Time-series data are mainly examined in terms of change, prediction, classification, clustering, and similarity searching [22-23]. Thus, this study combines the fuzzy clustering algorithm with the fuzzy time-series algorithm according to the characteristics of the influential factors in the energy consumption of pure electric buses to conduct similarity searching and to assess fuzzy time-series energy consumption.

Energy consumption levels and influential factors are classified based on specialist opinions and the actual mean data of operations to enhance the qualitative description of energy consumption [24-25]. Therefore, this study identifies typical energy consumption samples to label the initial clustering center. Furthermore, it clusters other sample data to classify energy consumption data effectively and to establish the analytical model of time-series energy consumption based on fuzzy clustering.

Every sample point belongs to a certain class in each iteration step of the clustering algorithm. The fuzzy clustering algorithm simplifies the terms and assumes its fuzzy membership to a certain class. This membership function is equal to the $\hat{P}\left(\omega_{i} \mid x_{j}, \hat{\theta}\right)$ of Bayes formula for normal distribution defuzzification value.

$$
\hat{P}\left(\omega_{i} \mid x_{j}, \hat{\theta}\right)=\frac{p\left(x_{j} \mid \omega_{i}, \hat{\theta}_{i}\right) \hat{P}\left(\omega_{i}\right)}{\sum_{j=1}^{c} p\left(x_{j} \mid \omega_{j}, \hat{\theta}_{j}\right) \hat{P}\left(\omega_{j}\right)}
$$

where $\hat{\theta}$ is the parameter vector of the membership function, $\hat{P}\left(\omega_{i} \mid x_{j}, \hat{\theta}\right)$ is normal distribution value of defuzzification, $p\left(x_{j} \mid \omega_{i}, \hat{\theta}_{i}\right)$ is maximum-likelihood, $\hat{P}\left(\omega_{i}\right)$ is prior probability.

$N$ represents the number of elements in the data set and $c$ denotes the number of clustering centres with regard to the data set of the influential factors in the energy consumption of pure electric buses $X=\left\{x_{1}, x_{2}, \cdots, x_{N}\right\}$. The minimum global cost function is expressed as follows:

$$
\begin{aligned}
& J_{f u z}(U, V)=\sum_{i=1}^{c} \sum_{j=1}^{n}\left[\hat{P}\left(\omega_{i} \mid x_{j}, \hat{\theta}\right)\right]^{b}\left\|x_{j}-\mu_{i}\right\|^{2} \\
& \text { s.t. }\left\{\begin{array}{l}
\sum_{i=1}^{c} \hat{P}\left(\omega_{i} \mid x_{j}, \hat{\theta}\right)=1, \forall j \\
\hat{P}\left(\omega_{i} \mid x_{j}, \hat{\theta}\right) \in[0,1], \forall i, j \\
\sum_{j=1}^{N} \hat{P}\left(\omega_{i} \mid x_{j}, \hat{\theta}\right)>1, \forall i
\end{array}\right.
\end{aligned}
$$

where $V=\left\{v_{1}, v_{2}, \cdots, v_{c}\right\} ; v_{i}$ represents the Centre vector of class $\omega_{i} ; \mu_{i}$ denotes the mean value of normal distribution, which is the clustering Centre; and $b$ corresponds to a free parameter that controls the mixing degrees of different classes, which is weight $b \in(1, \infty)$. The clustering membership of each sample point is normalized as follows:

$\sum_{i=0}^{c} \hat{P}\left(\omega_{i} \mid x_{j}\right)=1 \quad i=1, \cdots, c ; j=1, \cdots, N$

Classic time series models [26-27] such as autoregressive, modified moving average, autoregressive-moving-average and autoregressive integrated moving average normally obtain the dynamic, time-series data of observed objects through observation, investigation, statistics, and sampling. These data are objectively described by the curve-fitting method. However, most of these models are applicable only to data with relatively simple predictive results, such as stock, schooling, generalized Pareto distribution estimation, and climate. Furthermore, they cannot accurately describe the complex and fuzzy conditions of the energy consumption data obtained from pure electric buses, which are influenced by additional factors and generate complex predictive results. These models are normally affected, and their predictive results are not consistently optimal. To resolve this problem, this study introduces the membership weight matrix and uses the membership component of the observation value as the fuzzy matrix of the weights to predict and generate the 
fuzzy time-series model in fuzzy clustering. No additional predictive rules are required to improve prediction accuracy. The weight matrix of influential factors reflects the correlation and degree of the influence of these factors, whereas the matrix of overall energy consumption indicates the energy consumption conditions while travelling on the road between the nearest bus stops.

Energy consumption can be classified into five stages on the road between the nearest bus stops using the normal distribution algorithm based on actual observation values and clustering centers. These stages are extremely high, high, normal, low, and extremely low. Assuming that the discourse domain of energy consumption is $A_{i}=\frac{f_{A_{i}}\left(u_{1}\right)}{u_{1}}+\frac{f_{A_{i}}\left(u_{2}\right)}{u_{2}}+\cdots+\frac{f_{A_{i}}\left(u_{n}\right)}{u_{n}}=\int_{U} \frac{f_{A_{i}}\left(u_{k}\right)}{u_{k}}, \forall u_{k} \in U, n=5, k=1,2, \cdots, 5 \quad$, the fuzzy set $A_{i}$ of the discourse domain $U$ can be expressed as $A_{i}=\frac{f_{A_{i}}\left(u_{1}\right)}{u_{1}}+\frac{f_{A_{i}}\left(u_{2}\right)}{u_{2}}+\cdots+\frac{f_{A_{i}}\left(u_{n}\right)}{u_{n}}=\int_{U} \frac{f_{A_{i}}\left(u_{k}\right)}{u_{k}}, \forall u_{k} \in U, n=5, k=1,2, \cdots, 5$ In this equation, $f_{A_{i}}$ represents the membership function of fuzzy set $A_{i}$ (this study selects an isosceles trapezoid from among triangles and trapezoids as the fuzzy function according to the characteristics of pure electric buses); the symbol "+" represents connector $f_{A_{i}}: U \rightarrow[0,1]$, and $\sum_{k=1}^{n} f_{A_{i}}\left(u_{k}\right)=1 \cdot u_{k}$ denotes an element of fuzzy set $A_{i}$; $f_{A_{i}}\left(u_{k}\right)$ corresponds to the membership degree of element $u_{k}$ in the fuzzy set $A_{i}$; and membership function $f_{A_{i}}\left(u_{k}\right)$ satisfies $f_{A_{i}}\left(u_{k}\right) \in[0,1], 1 \leq k \leq n$.

When a fuzzy set $R(t-1, t)$ satisfies $F(t)=F(t-1) \circ R(t-1, t)$, and then $F(t)$ can be derived from $F(t-1)$. In this equation, $" \circ "$ represents an operator of relational calculus. If $F(t-1)$ $=A_{i}$ and $F(t)=A_{i}$, then the fuzzy logic relation (FLR) between the two continual data $F(t-1)$ and $F(t)$ can be expressed as $F(t-1) \rightarrow F(t) . F(t-1)$ is the left-hand relation of the FLR and $F(t)$ is the right-hand relation [2427]. The FLRs of the energy consumption at all roads between the nearest bus stops alone can define fuzzy logic groups given actual pure electric buses. These FLRs are expressed as $F(t-1) \rightarrow F(t), t=1,2, \ldots, 17$. For the sole fuzzy time-series sequence, the weight value of energy consumption on the roads between the nearest bus stops is expressed as (5).

$$
\begin{aligned}
& W(t)=\left[w_{1}(t) w_{2}(t), \cdots w_{n}(t)\right] \\
&=\left[\frac{c_{1} E_{1}(t)}{c_{1} E_{1}(t)+c_{2} E_{2}(t)+\cdots+c_{n} E_{n}(t)}, \frac{c_{2} E_{2}(t)}{c_{1} E_{1}(t)+c_{2} E_{2}(t)+\cdots+c_{n} E_{n}(t)}, \cdots, \frac{c_{n} E_{n}(t)}{c_{1} E_{1}(t)+c_{2} E_{2}(t)+\cdots+c_{n} E_{n}(t)}\right] \\
&=\left[\frac{c_{1} E_{1}(t)}{\sum_{n=1}^{n} c_{n} E_{n}(t)}, \frac{c_{2} E_{2}(t)}{\sum_{n=1}^{n} c_{n} E_{n}(t)}, \cdots \frac{c_{n} E_{n}(t)}{\sum_{n=1}^{n} c_{n} E_{n}(t)}\right] \\
& \text { s.t. } \sum_{n=1}^{n} c_{n} E_{n}(t) y=128.313 x_{1}-411.546 x_{2}+32.541 x_{3}-0.001 x_{4}+0.262 x_{5}-13.447
\end{aligned}
$$

where $w_{n}(t)$ represents the weight value of the road between the nearest bus stops; $c_{n}$ denotes the degree of fuzzy membership that corresponds to the degree of energy consumption on the road between the nearest bus stops; $f_{A_{i}}\left(u_{k}\right)$ represents the corresponding normal distribution value of defuzzification; and $E_{n}(t)$ denotes the energy consumption value that corresponds to the clustering center on the road between the nearest bus stops.

The fuzzy time series of the energy consumption on the road between the nearest bus stops describes the calculation method of the overall distribution of the energy consumed by pure electric buses throughout a road trip. This distribution is expressed by dynamic weight value. Moreover, the fuzzy similarities are measured under the energy consumption conditions of the fuzzy clustering center on the road between the nearest bus stops to estimate the overall energy consumption conditions.

\section{Test and results \\ 4.1 Test data description}

The model of bus driver habits is established using the traffic state information uploaded by the automobile data recorder on the bus. This recorder is equipped with satellite positioning function, and the data fields it uploads include positioning information, speed, direction, lights, acceleration, and braking. The indices of driving habit, such as the acceleration and deceleration time ratios, can then be computed based on the uploaded data regarding the road traffic between the nearest bus stops. Furthermore, the index system of traffic operation is estimated according to the positions and speeds of floating vehicles (taxis and coaches).

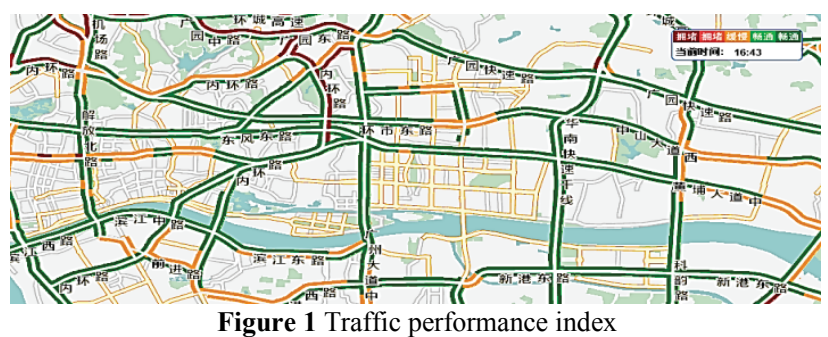

Fig. 1 illustrates real-time traffic operation index conditions at different times of the day. It also depicts the traffic conditions in terms of colour depth (from dark green to dark red) based on the classification rules of the index system of traffic evaluation in Guangzhou. These colours indicate highly smooth flow, smooth flow, slight traffic jam, jam, and serious jam. Their respective Traffic 
Performance Index (TPI) values are $0 \leq \mathrm{TPI}<2,2 \leq \mathrm{TPI}$

$<4,4 \leq \mathrm{TPI}<6,6 \leq \mathrm{TPI}<8$, and $8 \leq \mathrm{TPI} \leq 10$.

\subsection{Test results and analysis}

The research subject in this study is pure electric bus no. 801 in Guangzhou. The influential factor indices are measured to construct the model of driving mileage prediction for the pure electric bus based on the traffic performance index of bus stops. In the process, the driving conditions of pure electric buses on the route can be estimated. The pure electric bus must return to the station for battery change or recharge when SOC value is lower than or equal to $30 \%$ based on operation rules; thus, this study predicts the energy consumed on the road between the nearest bus stops given different minimum residual energy requirements in real operation conditions when complete energy consumption tests cannot be conducted. The predicted values are then compared with the real values. This study uses the data obtained from similar work days and times as samples to estimate residual energy consumption under the same conditions.

Six hundred and twenty-four pieces of energy consumption data are derived from pure electric buses with complete attributes in operation to describe the overall traffic performance index of the bus routes and energy consumption conditions. These buses complete their operational tasks on Tuesday mornings between 0700 and 0900 hours. The statistical results of some of the data on the attributes are described below:

Table 3 Statistics of the partial attributes of traffic jam indices and residual energy

\begin{tabular}{|c|c|c|c|c|c|c|c|c|}
\hline Traffic jam indices & \multicolumn{2}{|c|}{$\begin{array}{c}\text { Overall energy } \\
\text { consumption on the routes }\end{array}$} & \multicolumn{2}{|c|}{$\begin{array}{c}\text { Minimum temperature on } \\
\text { the bus }\end{array}$} & \multicolumn{2}{|c|}{$\begin{array}{l}\text { Maximum temperature of } \\
\text { the batteries }\end{array}$} & \multicolumn{2}{|c|}{$\begin{array}{l}\text { Mileage ratios of traffic } \\
\text { jams }\end{array}$} \\
\hline \multirow{5}{*}{$0 \leq \mathrm{TPI}<2$} & $\leq 40 \%$ & 4 & $\leq 20^{\circ} \mathrm{C}$ & 0 & $\geq 60^{\circ} \mathrm{C}$ & 18 & $\geq 30 \%$ & 13 \\
\hline & $40-50 \%$ & 39 & $20-26^{\circ} \mathrm{C}$ & 49 & $50-60{ }^{\circ} \mathrm{C}$ & 76 & $20-30 \%$ & 32 \\
\hline & $50-55 \%$ & 57 & $26-28^{\circ} \mathrm{C}$ & 59 & $40-50^{\circ} \mathrm{C}$ & 105 & $10-20 \%$ & 18 \\
\hline & $55-65 \%$ & 24 & $28-30{ }^{\circ} \mathrm{C}$ & 14 & $30-40^{\circ} \mathrm{C}$ & 4 & $5-10 \%$ & 23 \\
\hline & $\geq 65 \%$ & 1 & $\geq 30^{\circ} \mathrm{C}$ & 7 & $\leq 30^{\circ} \mathrm{C}$ & 0 & $\leq 5 \%$ & 12 \\
\hline \multirow{5}{*}{$2 \leq \mathrm{TPI}<4$} & $\leq 40 \%$ & 19 & $\leq 20^{\circ} \mathrm{C}$ & 0 & $\geq 60^{\circ} \mathrm{C}$ & 17 & $\geq 30 \%$ & 29 \\
\hline & $40-50 \%$ & 45 & $20-26^{\circ} \mathrm{C}$ & 98 & $50-60^{\circ} \mathrm{C}$ & 65 & $20-30 \%$ & 66 \\
\hline & $50-55 \%$ & 173 & $26-28^{\circ} \mathrm{C}$ & 116 & $40-50{ }^{\circ} \mathrm{C}$ & 56 & $10-20 \%$ & 110 \\
\hline & $55-65 \%$ & 21 & $28-30^{\circ} \mathrm{C}$ & 11 & $30-40^{\circ} \mathrm{C}$ & 2 & $5-10 \%$ & 34 \\
\hline & $\geq 65 \%$ & 2 & $\geq 30^{\circ} \mathrm{C}$ & 0 & $\leq 30^{\circ} \mathrm{C}$ & 0 & $\leq 5 \%$ & 7 \\
\hline \multirow{5}{*}{$4 \leq \mathrm{TPI}<6$} & $\leq 40 \%$ & 31 & $\leq 20^{\circ} \mathrm{C}$ & 0 & $\geq 60^{\circ} \mathrm{C}$ & 30 & $\geq 30 \%$ & 34 \\
\hline & $40-50 \%$ & 32 & $20-26^{\circ} \mathrm{C}$ & 107 & $50-60^{\circ} \mathrm{C}$ & 76 & $20-30 \%$ & 85 \\
\hline & $50-55 \%$ & 27 & $26-28^{\circ} \mathrm{C}$ & 68 & $40-50{ }^{\circ} \mathrm{C}$ & 32 & $10-20 \%$ & 22 \\
\hline & $55-65 \%$ & 10 & $28-30^{\circ} \mathrm{C}$ & 21 & $30-40^{\circ} \mathrm{C}$ & 2 & $5-10 \%$ & 1 \\
\hline & $\geq 65 \%$ & 2 & $\geq 30^{\circ} \mathrm{C}$ & 0 & $\leq 30^{\circ} \mathrm{C}$ & 0 & $\leq 5 \%$ & 0 \\
\hline \multirow{5}{*}{$6 \leq \mathrm{TPI}<8$} & $\leq 40 \%$ & 22 & $\leq 20^{\circ} \mathrm{C}$ & 0 & $\geq 60^{\circ} \mathrm{C}$ & 27 & $\geq 30 \%$ & 43 \\
\hline & $40-50 \%$ & 45 & $20-26^{\circ} \mathrm{C}$ & 31 & $50-60{ }^{\circ} \mathrm{C}$ & 52 & $20-30 \%$ & 45 \\
\hline & $50-55 \%$ & 37 & $26-28^{\circ} \mathrm{C}$ & 14 & $40-50^{\circ} \mathrm{C}$ & 32 & $10-20 \%$ & 25 \\
\hline & $55-65 \%$ & 8 & $28-30^{\circ} \mathrm{C}$ & 12 & $30-40^{\circ} \mathrm{C}$ & 3 & $5-10 \%$ & 0 \\
\hline & $\geq 65 \%$ & 0 & $\geq 30^{\circ} \mathrm{C}$ & 0 & $\leq 30^{\circ} \mathrm{C}$ & 0 & $\leq 5 \%$ & 0 \\
\hline \multirow{5}{*}{$8 \leq \mathrm{TPI} \leq 10$} & $\leq 40 \%$ & 7 & $\leq 20^{\circ} \mathrm{C}$ & 0 & $\geq 60^{\circ} \mathrm{C}$ & 11 & $\geq 30 \%$ & 10 \\
\hline & $40-50 \%$ & 10 & $20-26^{\circ} \mathrm{C}$ & 9 & $50-60^{\circ} \mathrm{C}$ & 6 & $20-30 \%$ & 13 \\
\hline & $50-55 \%$ & 8 & $26-28^{\circ} \mathrm{C}$ & 5 & $40-50{ }^{\circ} \mathrm{C}$ & 9 & $10-20 \%$ & 2 \\
\hline & $55-65 \%$ & 0 & $28-30^{\circ} \mathrm{C}$ & 3 & $30-40^{\circ} \mathrm{C}$ & 1 & $5-10 \%$ & 0 \\
\hline & $\geq 65 \%$ & 0 & $\geq 30^{\circ} \mathrm{C}$ & 0 & $\leq 30^{\circ} \mathrm{C}$ & 0 & $\leq 5 \%$ & 0 \\
\hline
\end{tabular}

Various influential factors of the traffic index system are inputted, including average speed on the main road, speed on the subsidiary road, traffic jam indices, mileage ratios of traffic jams, traffic jam duration, number of road sections that experience traffic jams between the nearest bus stops, total voltage in the battery management system, maximum voltage, minimum voltage, maximum battery temperature, minimum bus temperature, total current, and voltage difference. Residual energy is then outputted. The model is verified and the results analyzed using weekly data derived at the same time period. The fuzzy clustering algorithm mainly aims to determine the influential factors of different inputs to identify the relationship between various influential factor values of residual energy. The residual energy data can be predicted with the fuzzy timeseries algorithm.

The operational data of bus no. 801 in Guangzhou is obtained from between 0700 and 0900 hours and between 1700 and 1900 hours from Monday to Friday for the test.
A total of 1,932 pieces of complete attribute and traffic index data are generated by the corresponding bus stops, excluding missing data. Eight hundred and ninety-two pieces of information are derived in the morning between 0700 and 0900 hours; 49 are smooth traffic flow data $(0 \leq$ TPI $<2), 219$ are fairly smooth traffic flow data $(2 \leq$ TPI $<4), 337$ are light traffic jam data $(4 \leq$ TPI $<6), 217$ are medium traffic jam data $(6 \leq$ TPI $<8)$, and 70 are heavy traffic jam data $(8 \leq$ TPI $\leq 10)$. One thousand and forty pieces of data are collected between 1700 and 1900 hours; 34 are smooth traffic flow data $(0 \leq$ TPI $<2), 189$ are fairly smooth traffic flow data $(2 \leq \mathrm{TPI}<4), 422$ are light traffic jam data $(4 \leq$ TPI $<6), 312$ are medium traffic jam data $(6 \leq$ TPI $<8)$, and 83 are heavy traffic jam data $(8 \leq$ TPI $\leq 10)$. Tab. 4 displays the predicted energy consumption of buses in the process of completing operational tasks based on actual traffic performance index and comparison results. 
Table 4 Predicted residual energy

\begin{tabular}{|c|c|c|c|c|c|c|c|}
\hline \multirow[b]{2}{*}{$\begin{array}{l}\text { Time } \\
\text { duration }\end{array}$} & \multirow[b]{2}{*}{$\begin{array}{c}\text { Residual energy } \\
\text { value }\end{array}$} & \multicolumn{5}{|c|}{ Actual values } & \multirow[b]{2}{*}{ Accuracy } \\
\hline & & $\begin{array}{c}\text { Extremely } \\
\text { high } \\
\text { consumption }\end{array}$ & $\begin{array}{c}\text { High } \\
\text { consumption }\end{array}$ & $\begin{array}{c}\text { Normal } \\
\text { consumption }\end{array}$ & $\begin{array}{c}\text { Low } \\
\text { consumption }\end{array}$ & $\begin{array}{l}\text { Extremely low } \\
\text { consumption }\end{array}$ & \\
\hline \multirow{6}{*}{$\begin{array}{c}\text { AM: 7:00- } \\
\text { 9:00 }\end{array}$} & $\begin{array}{l}\text { Extremely high } \\
\text { consumption }\end{array}$ & 36 & 33 & 3 & 0 & 0 & $73.47 \%$ \\
\hline & $\begin{array}{c}\text { High } \\
\text { consumption }\end{array}$ & 10 & 166 & 47 & 17 & 0 & $75.80 \%$ \\
\hline & $\begin{array}{c}\text { Normal } \\
\text { consumption }\end{array}$ & 3 & 15 & 251 & 33 & 6 & $74.48 \%$ \\
\hline & $\begin{array}{c}\text { Low } \\
\text { consumption }\end{array}$ & 0 & 5 & 34 & 162 & 13 & $74.65 \%$ \\
\hline & $\begin{array}{l}\text { Extremely low } \\
\text { consumption }\end{array}$ & 0 & 0 & 2 & 5 & 51 & $72.86 \%$ \\
\hline & $\begin{array}{c}\text { Accurate total } \\
\text { value }\end{array}$ & \multicolumn{5}{|c|}{666} & $74.66 \%$ \\
\hline \multirow{6}{*}{$\begin{array}{c}\text { PM: } 5: 00- \\
7: 00\end{array}$} & $\begin{array}{l}\text { Extremely high } \\
\text { consumption }\end{array}$ & 24 & 29 & 9 & 0 & 0 & $70.59 \%$ \\
\hline & $\begin{array}{c}\text { High } \\
\text { consumption }\end{array}$ & 8 & 144 & 51 & 13 & 0 & $76.19 \%$ \\
\hline & $\begin{array}{c}\text { Normal } \\
\text { consumption }\end{array}$ & 2 & 13 & 335 & 43 & 11 & $79.38 \%$ \\
\hline & $\begin{array}{c}\text { Low } \\
\text { consumption }\end{array}$ & 0 & 3 & 25 & 231 & 20 & $74.04 \%$ \\
\hline & $\begin{array}{l}\text { Extremely low } \\
\text { consumption }\end{array}$ & 0 & 0 & 2 & 25 & 52 & $62.65 \%$ \\
\hline & $\begin{array}{c}\text { Accurate total } \\
\text { value }\end{array}$ & \multicolumn{5}{|c|}{786} & $75.58 \%$ \\
\hline
\end{tabular}

Thirty-three pieces of the predicted data obtained in the morning between 0700 and 0900 hours remain based on the "skip" errors in the confusion matrix. These data correspond to $3.70 \%$ of the total data. Similarly, 40 pieces of predicted data collected in the afternoon between 1700 and 1900 hours are retained. This value corresponds to $3.85 \%$ of total data and is classified as extremely low. The number of erroneous predictions in the confusion matrix is lower below the diagonal than above the diagonal with respect to the data obtained in the morning and in the afternoon (between 0700 and 0900 and between 1700 and 1900 hours), which indicates that the algorithm can easily mistake the low energy consumed by the battery for high consumption. Therefore, the method proposed in this study can describe the spatial-temporal relationship between traffic performance index and the energy consumption of pure electric buses accurately. As a result, it is a significant reference for the analysis of traffic conditions, energy conservation, and emission reduction for buses.

TPI has enormous impact on the energy consumption of the pure electric buses. Tab. 4 is the statistic of the energy consumption. In order to describe the relation between TPI and the operation of pure electric buses, Tab. 5 lists the relation between the remaining energy level and TPI. It is important to note that TPI is the representation of the traffic congestion of the whole city, but for bus lines, it has some matching and adaptive problem. For the time series based TPI, on the one hand, it has enormous impact on the specific line position. On the other hand, it just makes statistic based on the mean value of TPI between the departure time and return time of the whole bus line operation, which has only significance for statistic but no time characteristic.

Table 5 Comparison between remaining energy consumption and TPI

\begin{tabular}{|c|c|c|c|c|c|c|}
\hline $\begin{array}{c}\text { Time } \\
\text { duration }\end{array}$ & Residual energy value & $\begin{array}{c}\text { Extremely } \\
\text { high } \\
\text { consumption }\end{array}$ & $\begin{array}{c}\text { High } \\
\text { consumption }\end{array}$ & $\begin{array}{c}\text { Normal } \\
\text { consumption }\end{array}$ & $\begin{array}{c}\text { Low } \\
\text { consumption }\end{array}$ & $\begin{array}{c}\text { Extremely low } \\
\text { consumption }\end{array}$ \\
\hline \multirow{5}{*}{$\begin{array}{c}\text { AM: 7:00- } \\
\text { 9:00 }\end{array}$} & heavy traffic jam data $(6 \leq$ TPI $\leq 10)$ & 26 & 44 & 19 & 12 & 1 \\
\hline & medium traffic jam data $(6 \leq \mathrm{TPI}<8)$ & 16 & 108 & 32 & 25 & 3 \\
\hline & light traffic jam data $(4 \leq \mathrm{TPI}<6)$ & 3 & 24 & 198 & 43 & 4 \\
\hline & smooth traffic flow data $(2 \leq$ TPI $<4)$ & 3 & 38 & 72 & 115 & 23 \\
\hline & traffic flow data $(0 \leq$ TPI $<2)$ & 1 & 5 & 16 & 22 & 39 \\
\hline \multirow{5}{*}{$\begin{array}{c}\text { PM: 5:00- } \\
\text { 7:00 }\end{array}$} & heavy traffic jam data $(6 \leq$ TPI $\leq 10)$ & 14 & 45 & 32 & 42 & 3 \\
\hline & medium traffic jam data $(6 \leq$ TPI $<8)$ & 11 & 91 & 49 & 57 & 3 \\
\hline & light traffic jam data $(4 \leq \mathrm{TPI}<6)$ & 3 & 38 & 213 & 65 & 10 \\
\hline & smooth traffic flow data $(2 \leq$ TPI $<4)$ & 4 & 9 & 97 & 105 & 28 \\
\hline & traffic flow data $(0 \leq$ TPI $<2)$ & 2 & 6 & 31 & 43 & 39 \\
\hline
\end{tabular}

Tab. 4 exhibits the predicted general energy consumption of buses in the process of completing operational tasks. However, it does not include the predicted energy consumption values between the nearest bus stops. These predictions are generated under the conditions of the various road sections between the 
nearest bus stops given the operational data of bus no. 801 in Guangzhou. These data are gathered on a Wednesday between 0700 and 0900 hours in the morning and between 1700 and 1900 hours in the afternoon. Table 5 lists the relation between remaining energy consumption and TPI. TPI is updated once per minute, but the time of the pure electric bus between departure and return is updated once more than 2 hours. Therefore, because of the time characteristics of TPI, the statistic of the whole bus line lost its significance for prediction.

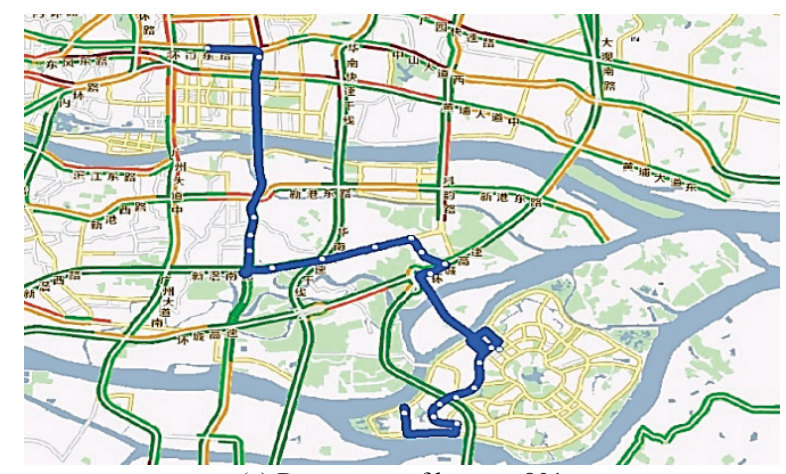

(a) Route map of bus no. 801

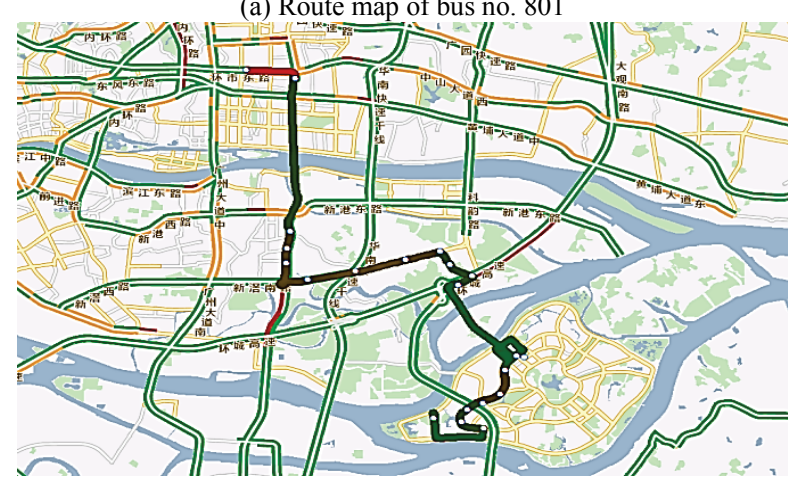

(b) Actual values (morning peak)

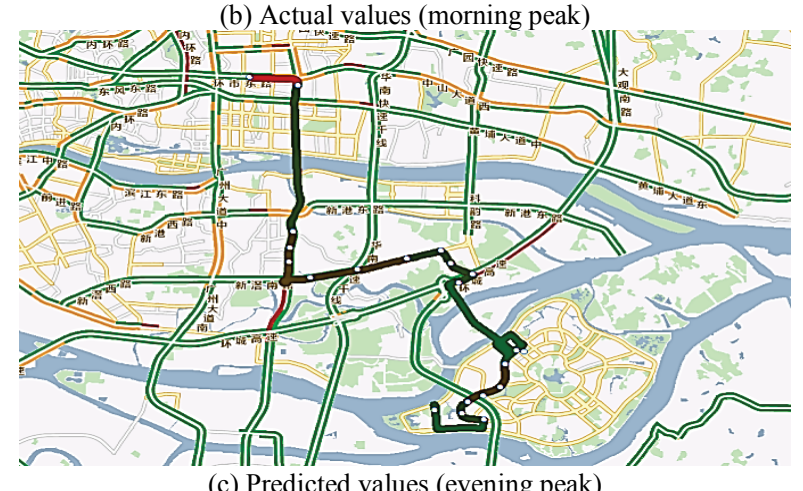

(c) Predicted values (evening peak)

Figure 2 Comparison of the actual and predicted values of energy consumption in pure electric buses

Fig. 2(a) shows the forward route diagram of bus no. 801, whereas Figure 2(b) depicts the actual energy consumption values of bus no. 801 on the road sections between the nearest bus stops on a Wednesday morning between 0700 and 0900 hours. Finally, Fig. 2(c) displays the corresponding predicted values. The different colours in Figs. 2(b) and 2(c) represent energy consumption. The dark blue colour denotes the road sections between the nearest bus stops, which in turn correspond to minimum energy consumption per $1000 \mathrm{~km}$. The dark red colour represents the road sections between the nearest bus stops, which in turn denote maximum energy consumption per $1000 \mathrm{~km}$. The median energy consumption between these two is marked in brown. The predicted values are highly accurate, and no energy consumption grades are skipped in the two erroneous judgments at the intersections of the main roads. Nonetheless, the judgment algorithm for main-road intersections should be expanded further to fully consider traffic lights and other factors.

\section{Conclusion}

A spatial-temporal prediction model of residual energy is constructed for pure electric buses using the fuzzy clustering and fuzzy time-series algorithms. This model is based on the traffic performance index of the road sections between the nearest bus stops and the battery data in pure electric buses. It is a significant reference for the analysis of traffic conditions, energy conservation, and emission reduction for buses.

The object of this study is the pure electric buses in China's big cities. Considering the various factors affecting the energy consumption, the weather factors vary from place to place, the quality of automobile brand manufacturers is also different, other factors can be added Select the object mainly considering the complex influence of China big city traffic factors, especially the traffic characteristics of passenger traffic complexity, state of the tidal effect significantly, so to establish the analysis model is relatively complex. The traffic problems in other small and medium-sized cities in China have not yet been highlighted, so the application of this model in small and medium-sized cities can play a certain role, but it is not particularly significant. For new energy vehicles themselves, different external factors and different drivers' driving habits can directly affect energy consumption. According to the characteristics of the bus line and site, the bus also determines the applicability of different new energy vehicles on different lines.

The factors affecting the energy consumption used in this paper are summarized through literature search and other practical experience and there may be more factors that are ignored or difficult to digital description. The authors will in the future further study the impact of these factors for consolidation, expansion, screening, so as to establish a model to describe better $\mathrm{Su}$ snow pure electric bus energy consumption.

\section{Acknowledgements}

The research is supported by Science and Technology Planning Project of Guangdong Province, China (2012B091100345, 2013B010102018, 2013B090600152, 2014B010112008, 2015B010106001, 2015B010129003, 2016B010109007), Pearl River S\&T Nova Program of Guangzhou (201610010034), Science and Technology Program of Guangzhou, China (2014Y2-00044) and the Science Program of General Administration of Quality Supervision, Inspection and Quarantine the People's Republic of China (2014IK183).

\section{References}

[1] Luo, Y. T.; Xie, B.; He X. C. Identification of parameters of lithium battery packs for electric buses and SOC estimation. // Journal of South China University of 
Technology (Natural Science Edition), 40, 12(2012), pp. 79-86.

[2] Tian, T.; Li, X. Z.; Li, H. M. Improvement model of lithium iron phosphate battery and SOC estimation. // Journal of Hefei University of Technology (Natural Science Edition), 35, 9(2012), pp. 1192-1196

[3] Li, Z.; Lu, L. G.; Ouyang, G. M. Comparison of methods for increasing ampere-hour to estimate the battery SOC accuracy. // Journal of Tsinghua University (Natural Science Edition), 50, 8(2010), pp. 1293-1297.

[4] Bingham, C.; Walsh, C.; Carroll, S. Impact of driving characteristics on electric vehicle energy consumption and range. // IET Intelligent Transport Systems, 2012, 6(6):2935. https://doi.org/10.1049/iet-its.2010.0137

[5] Vaz, W.; Nandi, A. K. R.; Landers, R. G. et al. Electric vehicle range prediction for constant speed trip using multiobjective optimization. // Journal of Power Sources, 2015, 275:435-446. https://doi.org/10.1016/j.jpowsour.2014.11.043

[6] Hornstra, F.; Mulcahey, T. P.; Biwer, R. L. et al. A methodology to assess the impact of driving schedules and drive train characteristics on electric vehicle range. Peak Discharge, 1986.

[7] Oliva, J. A.; Weihrauch, C.; Bertram, T. Model-based remaining driving range prediction in electric vehicles by using particle filtering and Markov chain. // Electric Vehicle Symposium and Exhibition. IEEE, 2014:1-10.

[8] Niu, L. Y.; Shi, W.; Jiang, J. C. Analysis of model parameters for pure electric buses using lithium iron phosphate batteries. // Automobile Engineering, 35, 2(2013), pp. 127-132.

[9] Shi, W.; Jiang, J. C.; Li, S. Y. Research on SOC estimation methods for lithium iron phosphate batteries. // Electronic Measurement and Instrument Journal, 24, 8(2010), pp. 769774. https://doi.org/10.3724/SP.J.1187.2010.00769

[10] Wang, X. T.; Yang, Z. J.; Wang, Y. N. The application of dual Kalman filtering algorithm to the SOC estimation of lithium batteries. // Instrument and Meter Journal, 34, 8(2013), pp. 1732-1739.

[11] Wen, J. P.; Jiang, J. C.; Wen, F. The application of Kalman algorithm to the SOC estimation of pure electric buses and the analysis of errors in application. // Automobile Engineering, 32, 3(2010), pp. 188-193.

[12] Xu, L.; Wang, J. P.; Chen, Q. S. Kalman filtering state of charge estimation for battery management system based on a stochastic fuzzy neural network battery model. // Electrical Power and Energy Systems, 53, 1(2012), pp. 3339. https://doi.org/10.1016/j.enconman.2011.06.003

[13] He, H. W.; Xiong, R.; Zhang, X. W.; Sun, F. State-ofcharge estimation of the lithium-ion battery using an adaptive extended Kalman filter based on an improved the venin model. // IEEE Transactions on Vehicular Technology, 60, 4 (2011), pp. 1461-1469. https://doi.org/10.1109/TVT.2011.2132812

[14] Li, Y.; Shi, Q. S.; Cui, N. X. A study of SOC estimation for the power batteries of new-type electric buses. // Electric and Electronic Technologies, 43, 5(2009), pp. 78-80.

[15] Mi, L.; Zhao, M. N.; Qin, J. L. SOC model of power batteries for electric buses based on radial basis function neural network. // Journal of Chongqing University of Technology (Natural Science Edition), 25, 10(2011), pp. 15.

[16] Čokorilo, O.; Luca, M. D.; Acqua, Dell G. Aircraft safety analysis using clustering algorithms. // Journal of Risk Research, 17, 10(2014), pp. 1325-1340. https://doi.org/10.1080/13669877.2013.879493

[17] Zheng, S. J.; Yang, J. F. Research on the calculation methods for traffic jam evaluation indexes in China and abroad. // Highways and Auto Transport, 30, 3(2014), pp. $57-61$.
[18] Urban road traffic evaluation index system by Beijing Quality and Technical Supervision Bureau, Beijing Quality and Technical Supervision Bureau, 2011.

[19] Urban road traffic evaluation index system by Guangzhou Quality and Technical Supervision Bureau, Guangzhou, Guangzhou Quality and Technical Supervision Bureau, 2013.

[20] Xu, W. L. A study of RBF neural network estimation algorithm for the driving mileage of pure electric buses, master degree thesis of Beijing Jiaotong University, 2012.

[21] Gianluca, D. A.; Francesca, R.; Biancardo, S. A. Risk-type density diagrams by crash type on two-lane rural roads. 16, 10(2013), pp. 1297-1314.

[22] Jin, L. A study of matching relation between the battery state of electric bus and the operation, master degree thesis of Beijing Jiaotong University, 2011.

[23] Li, C. C. Research on response intensity of financial time series based on fuzzy clustering to public information, master degree thesis of Kunming University of Technology, 2011.

[24] Yao, S. G.; Lei, L.; Deng, J. W.; Lu, S.; Zhang, W. Heat transfer mechanism in porous copper foam wick heat pipes using nanofluids. // International Journal of Heat and Technology, 33, 3(2015), pp. 133-138. https://doi.org/10.18280/ijht.330320

[25] Delmastro, C.; Mutani, G.; Schranz, L.; Vicentini, G. The role of urban form and socio-economic variables for estimating the building energy savings potential at the urban scale. // International Journal of Heat and Technology, 33, 4(2015), pp. 91-100. https://doi.org/10.18280/ijht.330412

[26] Prabakaran, K.; Sivapragasam, C.; Jeevapriya, C.; Narmatha, A. Forecasting Cultivated Areas and Production of Wheat in India Using ARIMA Model. // Golden Research Thoughts, 3, 3(2013), pp. 1-7. https://doi.org/10.9780/2231-5063/332013/2831

[27] Ayad, B.; Monfared, H.; Soori, Y. M.; Net, S. Prediction of Fatal Road Traffic Crashes in Iran Using The Box-Jenkins Time Series Model. // Journal of Asian Scientific Research, 3, 4(2013), pp. 425-430.

[28] Muhammad, H. L.; Riswan, E.; Zuhaimy, I. Modified Weighted for Enrollment Forecasting Based on Fuzzy Time Series. // MATEMATIKA, 25, 1(2009), pp. 67-78. https://doi.org/10.3923/jai.2011.110.118

[29] Ismail, Z.; Efendi, R. Enrollment Forecasting based on Modified Weight Fuzzy Time Series. // Journal of Artificial Intelligence, 4, 1(2011), pp. 110-118.

[30] Yu Tiffany, H. K.; Huarng, K. H. A Neural Network-based Fuzzy Time Series Model to Improve Forecasting. // Expert Systems with Applications, 37, 4(2010), pp. 3366-3372. https://doi.org/10.1016/j.eswa.2009.10.013

[31] Tiffany, H. K.; Yu Huarng, K. H. A Bivariate Fuzzy Time Series Model to Forecast the TAIEX. // Expert Systems with Applications, 34, 4(2008), pp. 2945-2952. https://doi.org/10.1016/j.eswa.2007.05.016

\section{Authors' addresses}

\section{Dr. Li Wang}

The School of Computer Software, Section A, Building 55, Tianjin University Beiyangyuan Campus, No. 135, Ya Guan Road, Jinnan District, Tianjin, 300354 China

E-mail: wangli@tju.edu.cn

\section{Dr. Jingfeng Yang, Corresponding Author}

Guangzhou Yuntu Information Technology CO, LTD, \& Open Laboratory of Geo-spatial Information Technology and Application of Guangdong Province, Guangzhou Institute of Geography, 100 Xianliezhong Road, Guangzhou 510070, China.

E-mail: jingfengyang@126.com 


\section{Dr. Nanfeng Zhang}

Senior Engineer, Chief Engineer of Guangzhou Entry Exit Inspection and Quarantine Bureau laboratory. Mechanical and electrical integration, vehicle detection and fault diagnosis.

Members of Society of automotive engineering of China, science and technology expert of Guangdong Provincial Department of Science and Technology, expert of Guangzhou City Auto Repair Association.

E-mail:nf zhang@126.com

\section{Dr. Ji Yang}

Open Laboratory of Geo-spatial Information Technology and Application of Guangdong Province, Guangzhou Institute of Geography, 100 Xianliezhong Road, Guangzhou 510070, China, E-mail:18438478@qq.com

\section{Dr. Yong $L i$}

Open Laboratory of Geo-spatial Information Technology and Application of Guangdong Province, Guangzhou Institute of Geography, 100 Xianliezhong Road, Guangzhou 510070, China E-mail: liyong@gdas.ac.cn

\section{Ms. Jiarong He}

Deputy Chief of integrated four division in Foshan municipal people's government office

E-mail: hejr@foshan.gov.cn

\section{Ms. Feng Yang}

Open Laboratory of Geo-spatial Information Technology and Application of Guangdong Province, Guangzhou Institute of Geography, 100 Xianliezhong Road, Guangzhou 510070, China E-mail: 13803039117@139.com

\section{Ms. Handong Zhou}

Guangzhou Yuntu Information Technology CO, LTD, \& Open Laboratory of Geo-spatial Information Technology and Application of Guangdong Province, Guangzhou Institute of Geography, 100 Xianliezhong Road, Guangzhou 510070, China

E-mail: 120262060@qq.com 